Article

\title{
DNA-Based Authentication and Metabolomics Analysis of Medicinal Plants Samples by DNA Barcoding and Ultra-High-Performance Liquid Chromatography/Triple Quadrupole Mass Spectrometry (UHPLC-MS)
}

\author{
Marta Sánchez, Elena González-Burgos@ ${ }^{\circledR}$, Pradeep Kumar Divakar \\ and M. Pilar Gómez-Serranillos * \\ Department of Pharmacology, Pharmacognosy and Botany, Faculty of Pharmacy, Universidad Complutense de \\ Madrid (UCM), 28040 Madrid, Spain; martas15@ucm.es (M.S.); elenagon@ucm.es (E.G.-B.); \\ pdivakar@farm.ucm.es (P.K.D.) \\ * Correspondence: pserra@ucm.es
}

Received: 28 October 2020; Accepted: 17 November 2020; Published: 18 November 2020

check for updates

\begin{abstract}
There is growing interest for medicinal plants in the world drug market. Particularly, Matricaria recutita L., Valeriana officinalis L., Tilia spp., and Camellia sinensis (L.) Kuntze are some of the most consumed medicinal plants for treatment of minor health problems. Medicinal plants are seen as natural and safe; however, they can cause interactions and produce adverse reactions. Moreover, there is lack of consensus in medicinal plants regulation worldwide. DNA barcoding and UHPLC-MS technique are increasingly used to correctly identify medicinal plants and guarantee their quality and therapeutic safety. We analyzed 33 samples of valerian, linden, tea, and chamomile acquired in pharmacies, supermarkets, and herbal shops by DNA barcoding and UHPLC-MS. DNA barcoding, using matk as a barcode marker, revealed that CH1 sold as Camellia sinensis was Blepharocalyx tweediei, and sample TS2 sold as linden belong to Malvales. On the other hand, UHPLC-MS analysis revealed the presence of bioactive compounds (apigenin-7-glucoside, acetoxy valerenic acid, valerenic acid, epigallocatechin, and tiliroside). However, none of samples met minimum content of these active principles (except for valerenic acid in VF3) according to the European Medicines Agency (EMA) and Real Spanish Pharmacopeia. In conclusion, this study revealed the need to incorporate DNA barcoding and HPLC-MS techniques in quality controls of medicinal plants.
\end{abstract}

Keywords: medicinal plants; DNA barcoding; matk; HPLC-MS method

\section{Introduction}

Medicinal plants constitute the basis of traditional and modern primary healthcare. Over $80 \%$ of the population, mainly of developing countries, depend on traditional and herbal medicine. Moreover, at least $25 \%$ of drugs in the modern pharmacopeia are derived from plants [1]. Furthermore, it is estimated that pharmacological activity has been evaluated in only 15\% of all 300,000 plant species identified [2]. The consumption of medicinal plants for disease prevention and health promotion has increased significantly in the last two decades [3]. The reasons that explain the rise in therapeutic use of medicinal plants are several. They include natural tendency in population, erroneous perception of its safety, lower economic cost compared to conventional medicines, and polypharmacy $[4,5]$. The high demand for medicinal plants is reflected in the economic data of world market. The global trade in herbs was over USD 83 billion in 2012, being especially high in India, China, and Germany [6,7]. These medicinal plants are available in pharmacies, supermarkets, and herbal shops [4,8]. 
These medicinal plants must meet standards of quality, safety, and efficacy. In this context, pharmacopeia monographs include tests and acceptance criteria ranging from botanical identification, pharmacognostic evaluation, and chemical characterization with chromatographic methods to evaluate the quality of herbal medicines [9]. However, one of the biggest difficulties related to quality is that commercial medicinal plants are crushed or powdered, being problematic to identify phenotype or part of the plant [10]. The DNA barcoding technique is postulated as an effective tool to overcome limitations in the quality controls of commercial medicinal plants. DNA-based techniques consist of using short DNA sequences from standardized gene regions (rbcL, matK, and ITS2) [11-13]. One of the great advantages of DNA barcoding technique is that the result is not influenced by harvesting period, growth condition, environmental factors, and sample age, among other factors [14-16]. Moreover, high-performance liquid chromatography (HPLC) and mass chromatography (MS) techniques are widely useful to identify and quantify bioactive compounds found in medicinal plants [14]. Therefore, the correct botanical identification by DNA barcoding and the precise bioactive compounds determination by HPLC-MS constitute an integrated approach to guarantee quality and safety of market medicinal plants [17-19].

Matricaria recutita L. (chamomile), Valeriana officinalis L. (valerian), Tilia spp. (linden), and Camellia sinensis (L.) Kuntze (tea) are found among the most consumed medicinal plants. They are commonly acquired in pharmacies, herbal shops, and supermarkets. Chamomile flowers as infusions have a beneficial effect on digestion; valerian root in capsules are used for reducing anxiety and a nervous state and improving sleep; linden leaves as infusions reduce anxiety symptoms; tea leaves as capsule or infusion bring relief from digestive problems [20].

The aim of the present work is to apply DNA barcoding and UHPLC-MS methods as a tool to evaluate the quality of market samples of Matricaria recutita, Valeriana officinalis, Tilia spp., and Camellia sinensis.

\section{Results and Discussion}

\subsection{DNA Barcoding Analysis}

Commercial herbal products can be adulterer, replaced, or suffer some kind of contamination [20,21]. Herbal products are sold as ground or powdered form of a raw herb, which makes correct botanical identification difficult [22]. DNA barcoding constitutes a very useful tool for quality control and, consequently, for clinical safety [23,24]. Molecular analyses is crucial for accurate and fast identification of medicinal plants, since the plant fragments sold in the market is difficult to identify using traditional methods especially due to lack of morphological features. Moreover, they often mixed with other plant materials, and in such cases, molecular analysis is one of the best approaches for accurate sample identification $[25,26]$.

In this study, the DNA barcode marker matk was used to identify four of the most consumed medicinal plants, which were $M$. recutita, V. officinalis, Tilia spp., and C. sinensis [27-29]. A total of 33 market samples (pharmacies, herbal shops, and supermarkets) were investigated (nine samples from $M$. recutita flowers, seven from $V$. officinalis root, nine from Tilia spp. Leaves, and eight from C. sinensis leaves). DNA was successfully extracted from 23 of 33 markets samples. Raw material conditions (i.e., very dry, storage quality) could explain why DNA could not be extracted in 10 of the samples. A total of eighteen new matk sequences were generated for 23 samples isolated from chamomile, linden, tea, and valeria acquired in different distribution channels. These matk sequences were aligned with 38 sequences downloaded from GenBank. A total of 10 sequences were in $C$. sinensis data matrix, 20 in M. recutita, nine in $V$. officinalis, and 17 in Tilia spp. The length of all newly generated matk sequences was above $700 \mathrm{bp}$. All new sequences generated for this study have been deposited in GenBank.

The results of the molecular phylogenetic and DNA barcoding analyses were largely congruent. In the phylogenetic analysis, all samples were grouped together forming monophyletic clades except 
for CH1, TS2, and VH2 samples (Figures S1-S4). The authenticity of these samples was confirmed with DNA barcoding analysis using the Barcode of Life Data (BOLD) system. The results of the BOLD system blast are depicted in Figures S5-S8. The sample codes MH1 to MH3, MF2, and MS1 to MS3 were identified as M. recutita; CH2 and CF3 as C. sinensis; VH1, VS1, and VF2 as Valeriana hirtella Kunth.; TH1 to TH3 resulted Tilia cordata Mill. (Table 1). The sample CH1 sold as C. sinensis did not correspond to this species but to Blepharocalyx tweediei [30] Berg. Blepharocalyx tweediei is a tree native to Argentina and Uruguay that is traditionally used as infusion for cough, bronchospasm, diarrhea, and other intestinal disorders. Further, TS2 sample sold as Linden matched with Malvales; no closely related species was detected. Remarkably, samples sold as V. officinalis and Tilia platyphyllos/europea Scop. were identified as Valeriana hirtella Kunth. and T. cordata, respectively. On the other hand, all samples sold as chamomile were correctly identified as Matricaria recutita. Therefore, our study has identified alterations in Camellia sinensis and Tilia spp. in one of the three and one of the four samples, respectively, of these two genera belonged to entirely different species/order. Figure 1 shows the DNA final barcode identification of the analyzed marked medicinal plants. A percentage of 36.4 of plant samples were identified as right species, $48.5 \%$ were incomplete samples, and $15.2 \%$ were consider as replacements. This work reveals the need for a correct botanical identification for valerian and linden to ensure the precise labeling. DNA-based sample authentication is necessary for market medicinal plants for correct identification $[13,31,32]$.

Table 1. Sample identification using the Barcode of Life Data (BOLD) systems.

\begin{tabular}{ccc}
\hline Sample Code & Labelled & BOLD System Identification \\
\hline MH1 & Matricaria & Matricaria recutita \\
\hline MH2 & Chamomile & Matricaria recutita \\
\hline MH3 & Matricaria chamomilla & Matricaria recutita \\
\hline MF2 & Chamomile & Matricaria recutita \\
\hline MS1 & Chamomile & Matricaria recutita \\
\hline MS2 & Matricaria recutita & Matricaria recutita \\
\hline MS3 & Chamomile & Matricaria recutita \\
\hline CH1 & Camellia sinensis & Blepharocalyx tweediei \\
\hline CH2 & Thea & Camellia sinensis \\
\hline CF3 & Thea & Camellia sinensis \\
\hline VH1 & Valeriana officinalis & Valeriana hirtella \\
\hline VS1 & Valeriana officinalis & Valeriana hirtella \\
\hline VF2 & Valeriana officinalis & Valeriana hirtella \\
\hline TH1 & Tilia platyphyllos & Tilia cordata \\
\hline TH2 & Linden & Tilia cordata \\
\hline TH3 & Tilia Europea & Tilia cordata \\
\hline TS2 & Malvales \\
\hline
\end{tabular}




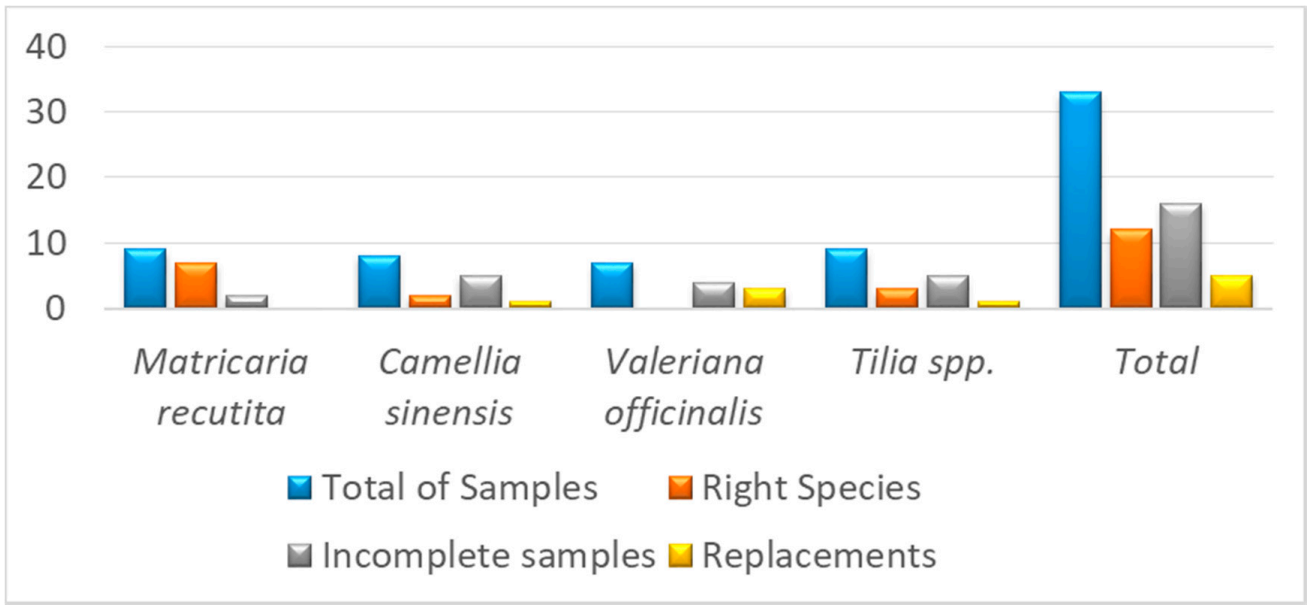

Figure 1. DNA-sequence-based identification of the analyzed medicinal plants marked samples.

\subsection{UHPLC/MS Analysis}

UHPLC-MS based metabolomics approach allows to qualitatively and quantitatively analyze all metabolites in medicinal plant species with high sensitivity and precision [33]. The first of these techniques (molecular assays) can only authenticate the medicinal plant, while the second assesses (chromatographic assays) its quality and can provide information on the presence and concentration of compounds with pharmacological activity, but can never determine the identity of the species in question (providing no direct evidence of fraud). The simultaneous use of both techniques is therefore an additional advantage for the evaluation of the quality of medicinal plants and thus for their efficacy and safety. The 33 market samples of the medicinal plants M. recutita, V. officinalis, Tilia spp. and $C$. sinensis were analyzed by HPLC-MS to identify and quantify the main bioactive compounds responsible for their pharmacological activity [34] (Tables 2-5, Figure 2). Particularly, the compound apigenin-7-glucoside was identified in $M$. recutita samples. The concentration of apigenin-7-glucoside ranged from 0.001 to $0.035 \%$. Most of the samples acquired in the different commercial establishments had an average content of this active principle of $0.003 \%$. Only two commercial samples of chamomile had a higher content in apigenin-7-glucoside, specifically MH1 sample acquired in an herbal shop $(0.035 \%)$ and MS3 sample acquired in a supermarket $(0.016 \%)$. The European Medicines Agency and the Real Spanish Pharmacopeia establish that apigenin-7-glucoside content should be at least $0.25 \%$ of dried drug [35,36], thus being the content in this bioactive compound lower in all analyzed samples. Moreover, previous studies have identified that the content for apigenin-7-glucoside in dry material of Matricaria chamomilla varied from 210 to $1110 \mathrm{mg} / 100 \mathrm{~g}$ using UPLC-UV method [37].

Table 2. Content of apigenin-7-glucoside in Matricaria recutita in samples labeled as acquired in pharmacies, herbal shops, and pharmacies. Data are expressed as means \pm standard deviations of triplicate independent analyses.

\begin{tabular}{cc}
\hline & Matricaria recutita $\mathbf{L}$. \\
\hline Sample & Apigenin-7-glucoside $(\mathbf{m g} / \mathbf{g})($ mean \pm SD) \\
\hline MH1 & $0.35 \pm 0.015$ \\
\hline MH2 & $0.02 \pm 0.004$ \\
\hline MH3 & $0.05 \pm 0.005$ \\
\hline MS1 & $0.07 \pm 0.004$ \\
\hline MS2 & $0.06 \pm 0.003$ \\
\hline MS3 & $0.16 \pm 0.009$ \\
\hline MF1 & $0.03 \pm 0.002$ \\
\hline MF2 & $0.01 \pm 0.004$ \\
\hline MF3 & $0.03 \pm 0.005$ \\
\hline
\end{tabular}


Table 3. Content of valerenic acid and acetoxyvalerenic acid in Valeriana in samples labeled as acquired in pharmacies, herbal shops, and pharmacies. Data are expressed as means \pm standard deviations of triplicate independent analyses.

\begin{tabular}{ccc}
\hline \multicolumn{3}{c}{ Valeriana Officinalis L. } \\
\hline Sample & $\begin{array}{c}\text { Acetoxyvalerenic Acid (mg/g) } \\
\text { (mean } \pm \text { SD) }\end{array}$ & Valerenic Acid (mg/g) (mean \pm SD) \\
\hline VH1 & $0.26 \pm 0.030$ & $1.09 \pm 0.017$ \\
\hline VH2 & $0.24 \pm 0.011$ & $1.15 \pm 0.017$ \\
\hline VH3 & $0.24 \pm 0.014$ & $1.01 \pm 0.020$ \\
\hline VF1 & $0.20 \pm 0.020$ & $0.48 \pm 0.015$ \\
\hline VF2 & $0.29 \pm 0.017$ & $0.78 \pm 0.026$ \\
\hline VF3 & $0.53 \pm 0.014$ & $1.67 \pm 0.030$ \\
\hline VS1 & $0.25 \pm 0.055$ & $0.84 \pm 0.015$ \\
\hline
\end{tabular}

Table 4. Content of epigallocatechin in Camellia sinensis in samples labeled as acquired in pharmacies, herbal shops, and pharmacies. Data are expressed as means \pm standard deviations of triplicate independent analyses.

\begin{tabular}{cc}
\hline & Camellia Sinensis $(\mathrm{L}$.$) Kuntze$ \\
\hline Sample & Epigallocatechin $(\mathbf{m g} / \mathbf{g})($ mean \pm SD) \\
\hline CH1 & $21.2 \pm 0.025$ \\
\hline CH2 & $47.2 \pm 0.015$ \\
\hline CH3 & $23.2 \pm 0.060$ \\
\hline CS1 & $32.9 \pm 0.025$ \\
\hline CS2 & $37.1 \pm 0.011$ \\
\hline CF1 & $15.1 \pm 0.020$ \\
\hline CF2 & $25.9 \pm 0.011$ \\
\hline CF3 & $25.5 \pm 0.030$ \\
\hline
\end{tabular}

Table 5. Content of tiliroside in Tilia in samples labeled as acquired in pharmacies, herbal shops, and pharmacies. Data are expressed as means \pm standard deviations of triplicate independent analyses.

\begin{tabular}{cc}
\hline \multicolumn{2}{c}{ Tilia spp. } \\
\hline Sample & Tiliroside $(\mathbf{m g} / \mathbf{g})(\mathbf{m e a n} \pm \mathbf{S D})$ \\
\hline TH1 & $0.32 \pm 0.056$ \\
\hline TH2 & $0.39 \pm 0.045$ \\
\hline TH3 & $0.08 \pm 0.020$ \\
\hline TS1 & $0.27 \pm 0.026$ \\
\hline TS2 & $0.42 \pm 0.032$ \\
\hline TS3 & $0.43 \pm 0.025$ \\
\hline TF1 & $0.23 \pm 0.020$ \\
\hline TF2 & $0.36 \pm 0.010$ \\
\hline TF3 & $0.35 \pm 0.011$ \\
\hline
\end{tabular}




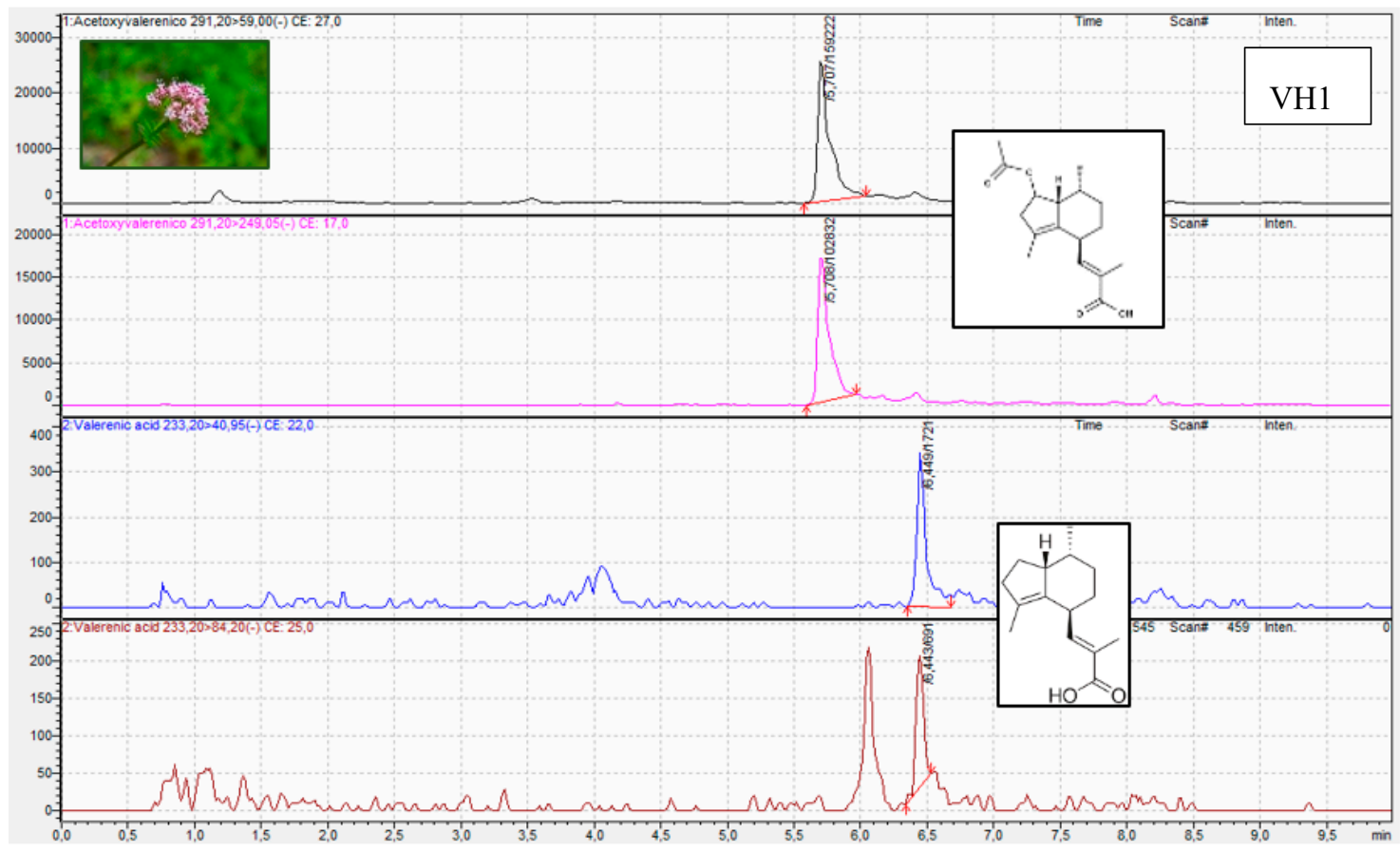

(A)

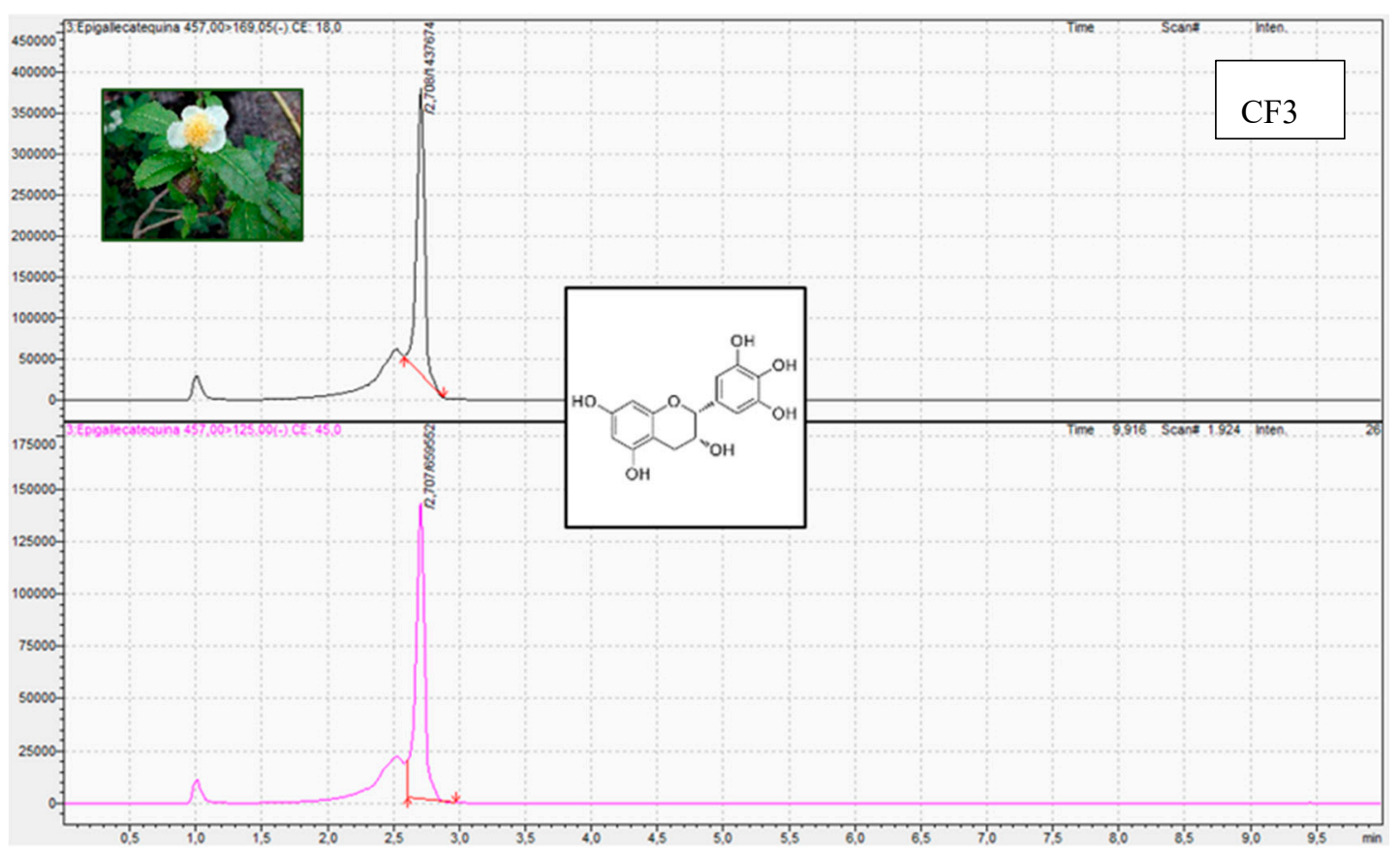

(B)

Figure 2. Cont. 


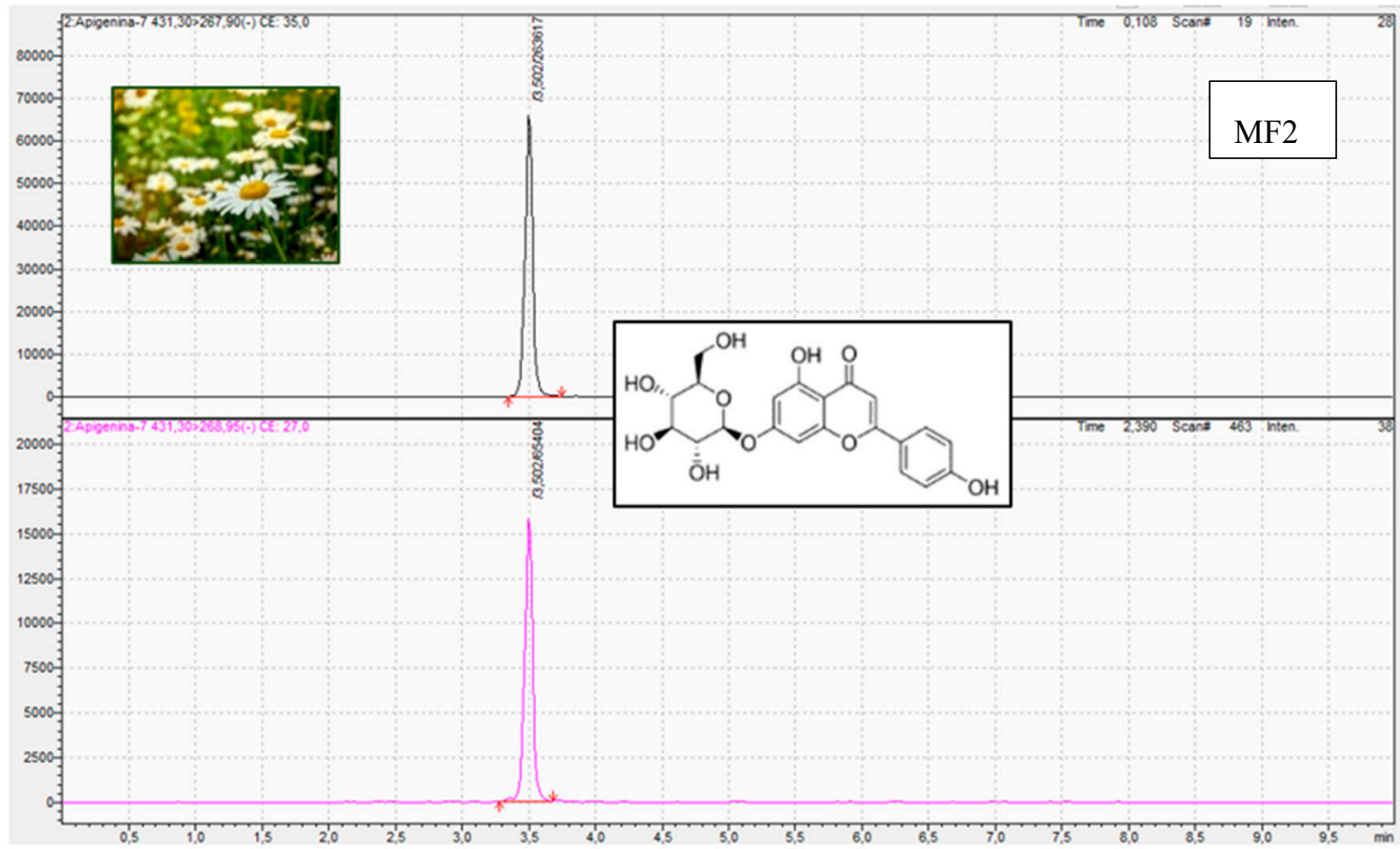

(C)

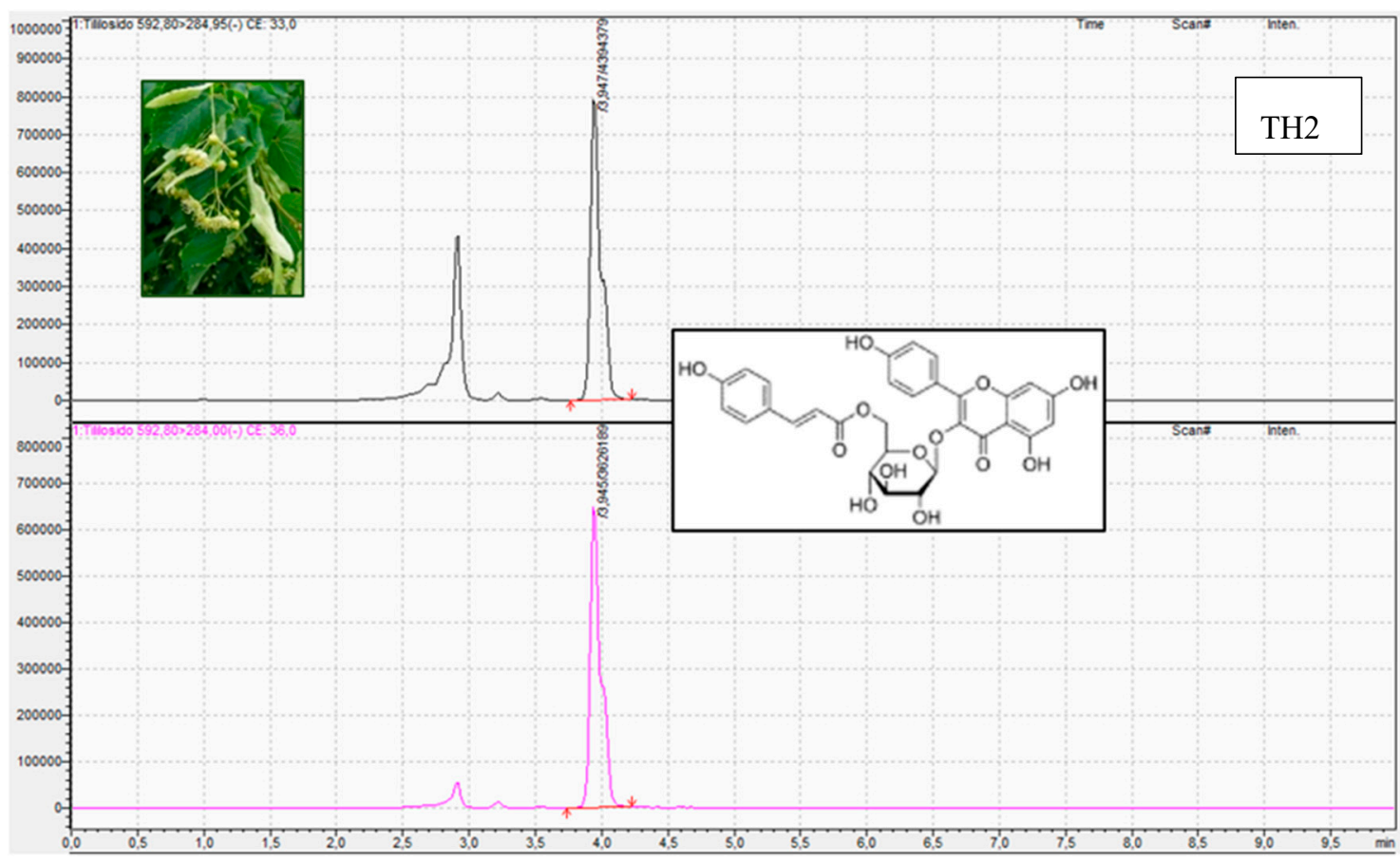

(D)

Figure 2. Representative UHPLC-ESI-QqQ-MS/MS chromatograms for (A) acetoxyvalerenic and valerenic acids presented in valerian samples, (B) epigallocatechin presented in tea samples, (C) apigenin presented in chamomile, and (D) tiliroside presented in linden.

For $V$. officinalis samples, the bioactive compounds identified were acetoxy valerenic acid and valerenic acid. Acetoxy valerenic acid concentration ranged from 0.020 to $0.053 \%$. The average content for this compound for all samples (except for VF3) was $0.025 \%$. The content in acetoxy valerenic acid for samples VF3 acquired in pharmacy was $0.053 \%$. On the other hand, a variable content of valerenic acid 
was identified among the different valerian samples (ranging from 0.048 to $0.167 \%$ ). Hence, the content of this bioactive compound was similar in those samples from herbal shops (from 0.101 to $0.115 \%$ ) and very different among pharmacy samples $(0.048,0.078$, and $0.167 \%)$. On the other hand, the content of valerenic acid in the valerian sample from supermarket was $0.084 \%$. According to the European Medicines Agency and the Real Spanish Pharmacopeia, the content in sesquiterpeneic acids should be not less than $0.17 \%$ expressed as valerenic acid $[36,38]$. The only sample that meets this requirement is VF3; this sample acquired in pharmacy could not be identified in the DNA barcoding study. Moreover, Navarrete et al. (2013) analyzed valerenic acid content in valerian species using liquid chromatography with ultraviolet detection. Particularly, the content of valerenic acid was $0.88 \%$ [39].

The compound epigallocatechin was identified and quantified in $C$. sinensis samples. Its content varied between 1.51 and $4.72 \%$. The lowest content corresponded to a pharmacy sample and the highest content to an herbal shop sample. The most common average content identified in four of six samples from pharmacies and supermarkets was $2.39 \%$. On the other hand, the epigallocatechin content of samples from supermarkets was very similar (3.29 and 3.71\%). The content in flavan-3-ols including epigallocatechin should range from 10-25\% of dried drug according to European Medicines Agency $[40,41]$. Previous works reported that the content in epigallocatechin was $4.62 \%$ in Camellia sinensis samples [42].

Finally, tiliroside was identified in tea samples with a content variation between 0.008 and $0.043 \%$. The low content of $0.008 \%$ was quantified in an herbal shop sample. The rest of linden samples had an average of $0.034 \%$. There are no data on tiliroside content neither in the European Medicines Agency nor in the Real Spanish Pharmacopeia [43]. The content of tiliroside has been identified to be higher in inflorescences that in leaves in Tilia cordata $(49.2 \mu \mathrm{g} / \mathrm{g}$ versus $16.1 \mu \mathrm{g} / \mathrm{g})$ [44].

The analysis of the secondary metabolites revealed that all the plant species analyzed, regardless of whether or not they had been correctly identified botanically, contained to a greater or lesser extent the bioactive compounds that were sought. This shows that these compounds are presented in other species of the same genus (i.e., Valeriana hirtella) and of other orders (i.e., Malvales). Specifically, the tiliroside has been identified in many different families including Malvaceae and Tiliaceae [44].

\section{Materials and Methods}

\subsection{Reagents}

Methanol HPLC grade was obtained from Panreac Química (Barcelona, Spain). Acetonitrile HPLC grade, formic acid HPLC grade, SYBR safe DNA gel stain, and the primers MatK-1RKIM-f and MatK-3FKIM-r were from Thermo Fisher Scientific (Runcorn, Cheshire, UK). Agarose MB 250 was purchased from Biotools Biotechnological and Medical Laboratories SA (Madrid, Spain). Apigenin-7-glucoside, epigallocatechin, and tiliroside were acquired from Extrasynthese (Genay Cedex, France). Acetoxy acid was from Sigma-Aldrich (St. Louis, MO, USA), and valerenic acid was from Chromadex (Irvine, CA, USA).

\subsection{Herbal Products}

The 33 samples of the four medicinal plants Matricaria recutita L., Valeriana officinalis L., Tilia spp., and Camellia sinensis (L.) Kuntze were acquired from supermarkets, herbal shops, and pharmacies located in the Autonomous Community of Madrid (Spain). Particularly, nine of these samples were from $M$. recutita flowers (3 samples from pharmacies, 3 samples from herbal shops, and 3 samples from supermarkets), seven from $V$. officinalis root (3 samples from pharmacies, 3 samples from herbal shops, and 1 sample from supermarkets), nine from Tilia spp. leaves ( 3 samples from pharmacies, 3 samples from herbal shops, and 3 samples from supermarkets), and eight from C. sinensis leaves (3 samples from pharmacies, 3 samples from herbal shops, and 2 samples from supermarkets) (Table 6). They were stored in conditions of temperature and ambient humidity. 
Table 6. Samples of the medicinal plants chamomile, valerian, tea, and linden acquired from supermarkets, herbal shops, and pharmacies located in the Autonomous Community of Madrid.

\begin{tabular}{cccccc}
\hline & Chamomile & & \multicolumn{2}{c}{ Valerian } \\
\hline Pharmacies & Herbal Shops & Supermarkets & Pharmacies & Herbal Shops & Supermarkets \\
\hline MF1 & MH1 & MS1 & VF1 & VH1 & VS1 \\
MF2 & MH2 & MS2 & VF2 & VH2 & \\
MF3 & MH3 & MS3 & VF3 & VH3 & \\
\hline \multicolumn{1}{c}{ Pharmacies } & Herbal Shops & Supermarkets & Pharmacies & Herbal Shops & Supermarkets \\
\hline TF1 & TH1 & TS1 & CF1 & CH1 & CS1 \\
TF2 & TH2 & TS2 & CF2 & CH2 & CS2 \\
TF3 & TH3 & TS3 & CF3 & CH3 & \\
\hline
\end{tabular}

\subsection{DNA Barcoding Analysis}

\subsubsection{DNA Extraction}

DNA was extracted from market medicinal plants samples of roots (V. officinalis), leaves (Tilia spp. and $C$. sinensis), and flowers ( $M$. recutita) using the Speed Tools tissue DNA extraction kit Biotools Biotechnological and Medical Laboratories following manufacturer's instructions. Approximately, $100 \mathrm{mg}$ of samples were pulverized with a sterile mortar in liquid nitrogen at room temperature and secondary metabolites were eliminated with methanol before starting DNA extraction. Then, samples were soaked in methanol for $2 \mathrm{~h}$ to remove potential secondary metabolites and dried overnight. Later, samples were incubated into lysis buffer initially at $65^{\circ} \mathrm{C}$ for $30 \mathrm{~min}$. In addition, root material samples were kept at room temperature overnight. After DNA extraction, samples were revealed in a $1 \%$ agarose gel stained with SYBR safe to check DNA quality [18].

\subsubsection{PCR and Sequencing}

Matk was chosen in this study, since it is one of the universal DNA barcode markers for land plants [25]. The matK gene of chloroplast is $1500 \mathrm{bp}$ long, located within the intron of the trnK. Since this gene is larger in length, a fragment of this is used for DNA barcoding analysis. Further, the gene contains high substitution rates within the species and is a potential candidate for DNA barcoding studies [11]. PCR amplifications of matk were performed using specific primers MatK-1RKIM-f and MatK-3FKIM-r (Ki-Joong Kim, pers. comm.). The reaction mixture ( $25 \mu \mathrm{L}$ final volume) contained $5 \mu \mathrm{L}$ of DNA (1:10), $4.5 \mu \mathrm{L}$ sterile water, $12.5 \mu \mathrm{L}$ REDTaq ReadyMix PCR Reaction M, and $1.5 \mu \mathrm{L}$ of each primer (forward and reverse) at $10 \mu \mathrm{M}$. PCR amplifications were carried out in a Techne R TC-3000 thermal cycler with the following conditions: one initial heating step of $45 \mathrm{~s}$ at $98^{\circ} \mathrm{C}$, followed by 35 cycles of $10 \mathrm{~s}$ at $98{ }^{\circ} \mathrm{C}, 30 \mathrm{~s}$ at $54^{\circ} \mathrm{C}$, and $40 \mathrm{~s}$ at $72{ }^{\circ} \mathrm{C}$. A final extension step of $10 \mathrm{~min}$ at $72{ }^{\circ} \mathrm{C}$ was added, after which samples were kept at $4{ }^{\circ} \mathrm{C}$.

Once PCR amplification is completed, a 1\% agarose gel stained with SYBR safe was used to visualize DNA. PCR products were purified by Speed-Tools PCR Clean Up (Biotools Biotechnological and Medical Laboratories SA, Madrid, Spain) kit following the manufacturer's instructions, and sequencing was performed with labelling using BigDye Terminator v. 3.1 Kit (Applied Biosystems, Madrid, Spain) as follows: 35 cycles of $20 \mathrm{sec}$ at $94{ }^{\circ} \mathrm{C}, 20 \mathrm{sec}$ at $48^{\circ} \mathrm{C}$, and $4 \mathrm{~min}$ at $60^{\circ} \mathrm{C}$. Sequences were obtained in an ABI PRISM 3130 Genetic Analyzer (Life Technologies, Alcobendas, Madrid, Spain). This is a standard approach to analyze PCR products.

\subsubsection{Data Analysis}

First, DNA sequences were assembled and manually adjusted in BioEdit sequence alignment editor software (v 7.2). Then, a second edition and assembly of the sequence fragments was made 
with the program SeqMan v.7 (Lasergene R, DNASTAR, Madison, WI, USA). Sequence identity was assessed using the mega-BLAST search function in GenBank $[45,46]$. Sequences with equal and above 95\% similarity were downloaded from the GenBank and aligned with the newly generated sequences for this study. Separate dataset for each taxa viz. M. recutita, V. officinalis, Tilia spp., and C. sinensis were prepared for phylogenetic analysis. Each dataset was aligned using MAFFT v.7 [47] implementing the G-INS-I alignment algorithm, "1PAM/K $=2$ " scoring matrix with an offset value of 0.0 , and the remaining parameters set to default values. The ambiguous regions in the matk alignment were assessed and removed using the least stringent option in Gblocks v.0.91b [48]. The alignments were analyzed using the maximum likelihood approach with RAxML v.8.2.6 program [49] as implemented on the CIPRES Web Portal, with the GTRGAMMA model. Nodal support was evaluated using 1000 bootstrap pseudoreplicates. The maximum likelihood (ML) trees were mid-point rooted. Phylogenetic trees were drawn using FigTree v.1.4.2 [50]. Moreover, sample identification was also assessed using a genetic distance-based blast option on the Barcode of Life Data System (BOLD Systems v3) [51]. The default setting was used for BLAST algorithm of the standard BOLD identification engine for mat $K$ sequences.

\subsection{UHPLC-MS/MS Analysis}

Samples were previously pulverized with a mortar and pestle sterile. Thirty milligrams of each medicinal plant samples were dissolved in $1 \mathrm{~mL}$ of ethanol/water $70 / 30 \%(v / v)$. Then, chamomile, linden, and tea samples were diluted 1:5 or 1:500, and valerian samples were diluted 1:4. HPLC standards were prepared at a concentration of $20 \mathrm{mg} / \mathrm{L}$ in methanol HPLC grade. Dilutions were prepared in a range of 0.05 to $1 \mathrm{mg} / \mathrm{L}$ in ethanol/water $70 / 30 \%(v / v)[52,53]$.

An ultra-high-performance liquid chromatography coupled with triple quadrupole mass spectrometry technique (UHPLC-QqQ-MS/MS) was developed using a LC-QQQ 8030 equipment (Shimazdu, Tokyo, Japan). The column was Phenomenex Gemini 5u C18 110A, $150 \times 2 \mathrm{~mm}$ (Phenomenex, Alcobendas, Spain). The gradient mode was 7 min 5-95\% Phase B; 8 min 95\% Phase B; 8.5 min 5\% Phase B using acetonitrile; in Phase A 0.1\% formic acid in water. The flow rate was $0.5 \mathrm{~mL} / \mathrm{min}$ and the infection volume was $10 \mu \mathrm{l}$ for all medicinal plant samples, except for valerian, which was an injection volume of $20 \mu \mathrm{L}$.

Regarding LC-MS analysis, the mass spectrometer electrospray capillary voltage was maintained at $4.0 \mathrm{kV}$ and the drying gas temperature at $250{ }^{\circ} \mathrm{C}$ with a flow rate of $15 \mathrm{~mL} / \mathrm{min}$. Nebulizer working flow was set at $1.5 \mathrm{~mL} / \mathrm{min}$. Nitrogen was used as both nebulizing and drying gas. Detection was carried out in Multiple reaction monitoring (MRM) mode, with a dwell time of $100 \mathrm{~ms}$ by monitoring three selective transitions for each parent compound. MRM transitions and their collision energy (CE) are shown in Table 7. The sample injection volume was $10 \mu \mathrm{L}$.

Data are expressed as means \pm standard deviations of triplicate independent analyses.

Table 7. Multiple reaction monitoring (MRM) transitions and $t$ collision energy conditions.

\begin{tabular}{cclc}
\hline Active Compound & Transition & CE & Dwell (msec) \\
\hline \multirow{2}{*}{ Acetoxyalerenic acid } & $291.3>59.00$ & $27 \mathrm{~V}$ & 100 \\
\cline { 2 - 4 } & $291.3>249.05$ & $17 \mathrm{~V}$ & 100 \\
\hline \multirow{2}{*}{ Valerenic acid } & $233.2>40.92$ & $22 \mathrm{~V}$ & 100 \\
\cline { 2 - 4 } & $233.2>84.20$ & $25 \mathrm{~V}$ & 100 \\
\hline \multirow{2}{*}{ Epigallocatechin } & $457>169.05$ & $18 \mathrm{~V}$ & 100 \\
\cline { 2 - 4 } & $457>125.00$ & $45 \mathrm{~V}$ & 100 \\
\hline Tiliroside & $592.8>284.95$ & $33 \mathrm{~V}$ & 100 \\
\cline { 2 - 4 } & $592.8>254.95$ & $55 \mathrm{~V}$ & 100 \\
\hline \multirow{2}{*}{ Apigenin-7-O-glucoside } & $431.3>267.90$ & $35 \mathrm{~V}$ & 100 \\
\cline { 2 - 4 } & $431.3>150.95$ & $52 \mathrm{~V}$ & 100 \\
\hline
\end{tabular}




\section{Conclusions}

DNA barcoding is revealed as an effective and necessary tool in the identification and authentication of plant species that are used in therapeutics. Since DNA barcoding does not provide qualitative or quantitative information on the metabolites of the plant raw material, its use together with chromatographic techniques such as HPLC-MS allows us to determine the precise identification of the species and the metabolic profile with great sensitivity and precision. The HPLC-MS technique combines the high resolution of ultra-high-performance liquid chromatography with high-resolution MS for molecular quantification. This technique has shown a high efficiency and resolution, a short time analysis, and increased sensitivity. The current work showed a high success rate in obtaining PCR amplification and sequencing of matk locus for the accurate sample identification of the market samples of medicinal plants. DNA barcoding demonstrated that the labeling of some medicinal plants acquired in different distribution channels is incorrect, demonstrating the need to apply DNA barcoding methods in the quality control of herbal products to ensure correct botanical identification and therefore ensure product quality. Moreover, the UHPLC-MS analysis displayed that all the analyzed samples presented the bioactive compounds (apigenin-7-glucoside, acetoxy valerenic acid, valerenic acid, epigallocatechin, and tiliroside) responsible for the pharmacological activity. This content was very variable for some plant species, as is the case of valerenic acid in valerian. In addition, none of the analyzed samples (except for valerenic acid in VF3) met the minimum content of these active principles according to the European Medicines Agency and the Real Spanish Pharmacopeia. This study shows the need to incorporate leading-edge molecular and analytical techniques for the quality control of plant species that are used in therapeutics to guarantee patient safety.

Future trends in the field of medicinal plants should be aimed at conducting more quality control studies in other widely consumed species and incorporating the combination of these molecular and analytical techniques in the plant industry for therapeutic purposes and even incorporating them into official documents (Pharmacopoeia, EMA).

Supplementary Materials: The following are available online at http://www.mdpi.com/2223-7747/9/11/1601/s1, Figure S1: Phylogenetic tress for M. recutita. Figure S2: Phylogenetic tress for V. officinalis. Figure S3: Phylogenetic tress for Tilia spp. Figure S4: Phylogenetic tress for C. sinensis. Figure S5: BOLD System for M. recutita. Figure S6: BOLD System for V. officinalis. Figure S7: BOLD System for Tilia spp. Figure S8: BOLD System for C. sinensis.

Author Contributions: Conceptualization, P.K.D. and M.P.G.-S.; methodology, P.K.D.; software, P.K.D.; validation, P.K.D. and M.S.; formal analysis, P.K.D. and E.G.-B.; investigation, M.S. and P.K.D.; writing-original draft preparation, P.K.D., M.S., and E.G.-B.; writing—review and editing, P.K.D. and E.G.-B.; supervision, M.P.G.-S. and P.K.D.; funding acquisition, P.K.D. All authors have read and agreed to the published version of the manuscript.

Funding: This research received no external funding.

Conflicts of Interest: The authors declare no conflict of interest.

\section{References}

1. WHO (World Health Organization). The World Traditional Medicines Situation. In Traditional Medicines: Global Situation, Issues and Challenges; WHO (World Health Organization): Geneva, Switzerland, 2011; pp. 1-14.

2. De Luca, V.; Salim, V.; Atsumi, S.M.; Yu, F. Mining the biodiversity of plants: A revolution in the making. Science 2012, 336, 1658-1661. [CrossRef]

3. Debbie, S.; Ladds, G.; Duez, P.; Williamson, E.; Chan, K. Pharmacovigilance of herbal medicine. J. Ethnopharmacol. 2012, 140, 513-518.

4. Ekor, M. The growing use of herbal medicines: Issues relating to adverse reactions and challenges in monitoring safety. Front. Pharmacol. 2014, 4, 177. [CrossRef] [PubMed]

5. Güney, O.I. Consumption attributes and preferences on medicinal and aromatic plants: A consumer segmentation analysis. Cienc. Rural 2019, 49, 5. [CrossRef]

6. Sofowora, A.; Ogunbodede, E.; Onayade, A. The role and place of medicinal plants in the strategies for disease prevention. Afr. J. Tradit. Complement. Altern. Med. 2013, 10, 210-229. [CrossRef] [PubMed] 
7. Allkin, B. Useful Plants-Medicines: At Least 28,187 Plant Species are Currently Recorded as Being of Medicinal Use. In State of the World's Plants; Willis, K.J., Ed.; Royal Botanic Gardens: London, UK, 2017.

8. Wei, S.; Luo, Z.; Cui, S.; Qiao, J.; Zhang, Z.; Zhang, L.; Fu, J.; Ma, X. Molecular Identification and Targeted Quantitative Analysis of Medicinal Materials from Uncaria Species by DNA Barcoding and LC-MS/MS. Molecules 2019, 24, 175. [CrossRef]

9. Neves, E.O.; de Sales, P.M.; Silveira, D. Pharmacopeial specifications and analytical data from post-marketing quality sampling and testing programs: A perspective beyond out-of-specification results. J. Pharm. Biomed. Anal. 2020, 178, 112935. [CrossRef]

10. Palhares, R.M.; Gonçalves, M.; Dos Santos, B.; Pereira, G.; das Graças, M.; Oliveira, G. Medicinal plants recommended by the world health organization: DNA barcode identification associated with chemical analyses guarantees their quality. PLoS ONE 2015, 10, e0127866. [CrossRef]

11. CBOL Plant Working Group. A DNA barcode for land plants. Proc. Natl. Acad. Sci. USA 2009, 106, 12794-12797. [CrossRef]

12. Tungmunnithum, D.; Renouard, S.; Drouet, S.; Blondeau, J.P.; Hano, C. A Critical Cross-Species Comparison of Pollen from Nelumbo nucifera Gaertn. vs. Nymphaea lotus L. for Authentication of Thai Medicinal Herbal Tea. Plants 2020, 9, 921.

13. Pawar, R.S.; Handy, S.M.; Cheng, R.; Shyong, N.; Grundel, E. Assessment of the Authenticity of Herbal Dietary Supplements: Comparison of Chemical and DNA Barcoding Methods. Planta Med. 2017, 83, 921-936. [CrossRef] [PubMed]

14. Abubakar, M.B.; Salleh, M.F.; Shamsir Omar, M.S.; Wagiran, A. DNA Barcoding and Chromatography Fingerprints for the Authentication of Botanicals in Herbal Medicinal Products. Evid. Based Complement Altern. Med. 2017, 1352948. [CrossRef]

15. Mili Bhargava, M.; Sharma, A. DNA barcoding in plants: Evolution and applications of in silico approaches and resources. Mol. Phylogenet. Evol. 2013, 67, 631-641. [CrossRef] [PubMed]

16. Ichim, M.C. The DNA-Based Authentication of Commercial Herbal Products Reveals Their Globally Widespread Adulteration. Front. Pharm. 2019, 10, 1227. [CrossRef] [PubMed]

17. Belščak-Cvitanović, A.; Valinger, D.; Benković, M.; Tušek, A.J.; Jurina, T.; Komes, D.; Kljusurić, J.G. Integrated approach for bioactive quality evaluation of medicinal plant extracts using HPLC-DAD, spectrophotometric, near infrared spectroscopy and chemometric techniques. Int. J. Food Prop. 2017, 20, 2463-2480. [CrossRef]

18. Zuo, Y.; Chen, Z.; Kondo, K.; Funamoto, T.; Wen, J.; Zhou, S. DNA barcoding of Panax species. Planta Med. 2011, 77, 182-187. [CrossRef]

19. Jianping, H.; Xiaohui Pang, X.; Baosheng, L.; Hui, Y.; Jingyuan, S.; Shilin, C. An authenticity survey of herbal medicines from markets in China using DNA barcoding. Sci. Rep. 2016, 6, 18723.

20. Sánchez, M.; González-Burgos, E.; Iglesias, I.; Lozano, R.; Gómez-Serranillos, M.P. Current uses and knowledge of medicinal plants in the Autonomous Community of Madrid (Spain): A descriptive cross-sectional study. BMC Complement. Med. Ther. 2020, 20, 306. [CrossRef]

21. Newmaster, S.G.; Grguric, M.; Shanmughanandhan, D.; Ramalingam, S.; Ragupathy, S. DNA barcoding detects contamination and substitution in North American herbal products. BMC Med. 2013, 11, 222. [CrossRef]

22. Wachtel-Galor, S.; Benzie, I.F.F. Herbal Medicine: An Introduction to Its History, Usage, Regulation, Current Trends, and Research Needs. In Herbal Medicine: Biomolecular and Clinical Aspects, 2nd ed.; Benzie, I.F.F., Wachtel-Galor, S., Eds.; CRC Press/Taylor \& Francis: Boca Raton, FL, USA, 2011; Chapter 1.

23. Howard, C.; Lockie-Williams, C.; Slater, A. Applied Barcoding: The Practicalities of DNA Testing for Herbals. Plants 2020, 9, 1150. [CrossRef]

24. Upton, R.; David, B.; Gafner, S.; Glasl, S. Botanical ingredient identification and quality assessment: Strengths and limitations of analytical techniques. Phytochem. Rev. 2019, 19, 1157-1177. [CrossRef]

25. Hausmann, A.; Haszprunar, G.; Hebert, P.D.N. DNA Barcoding the Geometrid Fauna of Bavaria (Lepidoptera): Successes, Surprises, and Questions. PLoS ONE 2011, 6, e17134. [CrossRef] [PubMed]

26. Janjua, S.; Fakhar-i-Abbas; William, K. DNA Mini-barcoding for wildlife trade control: A case study on identification of highly processed animal materials. Mitochondrial DNA 2016, 27, 544-546. [CrossRef] [PubMed] 
27. Ford, C.S.; Ayres, K.L.; Haider, N.; Toomey, N.; van-Alpen-Stahl, J.; Kelly, L.J.; Wikström, N.; Hollingsworth, P.M.; Duff, R.J.; Hoot, S.B.; et al. Selection of candidate DNA barcoding regions for use on land plants. Bot. J. Linn. Soc. 2009, 159, 1-11. [CrossRef]

28. Raclariu, A.C.; Paltinean, R.; Vlase, L.; Labarre, A.; Manzanilla, V.; Ichim, M.C.; Crisan, G.; Brysting, A.K.; Boer, H. Comparative authentication of Hypericum perforatum herbal products using DNA metabarcoding, TLC and HPLC-MS. Sci. Rep. 2017, 7, 1291. [CrossRef] [PubMed]

29. Raclariu, A.C.; Ţebrencu, C.E.; Ichim, M.C.; Ciupercǎ, O.T.; Brysting, A.K.; Boer, H. What's in the box? Authentication of Echinacea herbal products using DNA metabarcoding and HPTLC. Phytomedicine 2018, 15, 32-38. [CrossRef]

30. Hernández, J.; Raggone, M.; Bonazzola, P.; Bandoni, A.; Consolini, A. Antitussive, antispasmodic, bronchodilating and cardiac inotropic effects of the essential oil from Blepharocalyx salicifolius leaves. J. Ethnopharmacol. 2018, 210, 107-117. [CrossRef]

31. Ivanova, N.V.; Kuzmina, M.L.; Braukmann, T.W.A.; Borisenko, A.V.; Zakharov, E.V. Authentication of Herbal Supplements Using Next- Generation Sequencing. PLoS ONE 2016, 11, e0156426. [CrossRef]

32. Techen, N.; Parveen, I.; Pan, Z.; Khan, I.A. DNA barcoding of medicinal plant material for identification. Curr. Opin. Biotechnol. 2014, 25, 103-110. [CrossRef]

33. Li, X.; Zhang, X.; Ye, L.; Kang, Z.; Jia, D.; Yang, L.; Zhang, B. LC-MS-Based Metabolomic Approach Revealed the Significantly Different Metabolic Profiles of Five Commercial Truffle Species. Front. Microbiol. 2019, 10, 2227. [CrossRef]

34. Saleem, H.; Htar, T.T.; Naidu, R.; Anwar, S.; Zengin, G.; Locatelli, M.; Ahemad, N. HPLC-PDA Polyphenolic Quantification, UHPLC-MS Secondary Metabolite Composition, and In Vitro Enzyme Inhibition Potential of Bougainvillea glabra. Plants 2020, 9, 388. [CrossRef] [PubMed]

35. European Medicines Agency (EMA). Available online: https://www.ema.europa.eu/en/documents/herbalreport/final-assessment-report-matricaria-recutita-1-flos-matricaria-recutita-l-aetheroleum_en.pdf (accessed on 30 September 2020).

36. Real Farmacopea Española. Available online: https://extranet.boe.es/farmacopea/ (accessed on 1 October 2020).

37. Haghi, G.; Hatami, A.; Safaei, A.; Mehran, M. Analysis of phenolic compounds in Matricaria chamomilla and its extracts by UPLC-UV. RPS 2014, 9, 31-37. [PubMed]

38. European Medicines Agency (EMA). Available online: https://www.ema.europa.eu/en/documents/herbalreport/final-assessment-report-valeriana-officinalis-1-radix-valeriana-officinalis-1-aetheroleum_en.pdf (accessed on 30 September 2020).

39. Navarrete, A.; Avula, B.; Choi, Y.W.; Khan, I.A. Chemical fingerprinting of valeriana species: Simultaneous determination of valerenic acids, flavonoids, and phenylpropanoids using liquid chromatography with ultraviolet detection. J. AOAC Int. 2006, 89, 8-15. [CrossRef] [PubMed]

40. European Medicines Agency (EMA). Available online: https://www.ema.europa.eu/en/documents/herbalreport/draft-assessment-report-camellia-sinensis-1-kuntze-non-fermentatum-folium_en.pdf (accessed on 1 October 2020).

41. European Medicines Agency. Available online: https://www.ema.europa.eu/en/documents/scientific-guideline/ guideline-specifications-test-procedures-acceptance-criteria-herbal-substances-herbal-preparations/traditionalherbal-medicinal-products-revision-1_en.pdf (accessed on 25 September 2020).

42. Raghavendra, H.L.; Kumar, S.V.P.; Kekuda, T.R.P.; Ejeta, E.; Molla, B.; Anilakumar, K.R.; Khanum, F. HPLC method for chemical composition and in vitro antioxidant activity of Camellia sinensis Linn. Anal. Chem. Lett. 2011, 1, 361-369. [CrossRef]

43. Pieczykolan, A.; Pietrzak, W.; Nowak, R.; Pielczyk, J.; Lamacz, K. Optimization of Extraction Conditions for Determination of Tiliroside in Tilia L. Flowers Using an LC-ESI-MS/MS Method. J. Anal. Methods Chem. 2019, 9052425. [CrossRef]

44. Nowak, R. Separation and quantification of tiliroside from plant extracts by SPE/RP-HPLC. Pharm. Biol. 2003, 41, 627-630. [CrossRef]

45. Sayers, E.W.; Barrett, T.; Benson, D.A.; Bolton, E.; Bryant, S.H.; Canese, K.; Chetvernin, V.; Church, D.M.; Dicuccio, M.; Federhen, S.; et al. Database resources of the National Center for Biotechnology Information. Nucleic Acids Res. 2011, 39, D38-D51. [CrossRef]

46. Pedales, R.D.; Damatac, A.M.; Limbo, C.A.; Marquez, C.M.; Navarro, A.I.B.; Molina, J. DNA Barcoding of Philippine Herbal Medicinal Products. J. AOAC Int. 2016, 99, 1479-1489. [CrossRef] 
47. Katoh, K.; Toh, H. Recent developments in the MAFFT multiple sequence alignment program. Brief. Bioinform. 2008, 9, 286-298. [CrossRef]

48. Talavera, G.; Castresana, J. Improvement of phylogenies after removing divergent and ambiguously aligned blocks from protein sequence alignments. Syst. Biol. 2007, 56, 564-577. [CrossRef]

49. Stamatakis, A. RAxML version 8: A tool for phylogenetic analysis and post-analysis of large phylogenies. Bioinformatics 2014, 30, 1312-1313. [CrossRef] [PubMed]

50. Rambaut, A. “FigTree 1.2.2.". Available online: http://tree.bio.ed.ac.uk/software/figtree/ (accessed on 13 August 2020).

51. Ratnasingham, S. Hebert PDN. BOLD: The Barcode of Life Data System. Mol. Ecol. Notes 2007, 7, 355-364. [CrossRef] [PubMed]

52. Wang, C.; Zheng, Z.; Deng, X.; Ma, X.; Wang, S.; Liu, J.; Liu, Y.; Shi, J. Flexible and powerful strategy for qualitative and quantitative analysis of valepotriates in Valeriana jatamansi Jones using high-performance liquid chromatography with linear ion trap Orbitrap mass spectrometry. J. Sep. Sci. 2017, 40, 1906-1919. [CrossRef] [PubMed]

53. Scoparo, C.T.; de Souza, L.M.; Dartora, N.; Sassaki, G.L.; Gorin, P.A.; Iacomini, M. Analysis of Camellia sinensis green and black teas via ultra high performance liquid chromatography assisted by liquid-liquid partition and two-dimensional liquid chromatography (size exclusion $\times$ reversed phase). J. Chromatogr. A 2012, 1222, 29-37. [CrossRef] [PubMed]

Publisher's Note: MDPI stays neutral with regard to jurisdictional claims in published maps and institutional affiliations.

(C) 2020 by the authors. Licensee MDPI, Basel, Switzerland. This article is an open access article distributed under the terms and conditions of the Creative Commons Attribution (CC BY) license (http://creativecommons.org/licenses/by/4.0/). 